\title{
Discrimination performance in deprived and non-deprived rats as a function of pre-discrimination information'
}

REESA M. VAUGHTER, ZITA E. TYER AND CHARLES G. HALCOMB

TEXAS TECHNOLOGICAL COLLEGE

In an attempt to observe the Moss-Harlow effect, deprived and non-deprived albino rats were tested on a duo-dimension discrimination problem. Prior to discrimination trials $S_{s}$ were given one of three kinds of information; (1) trials to the rewarded cue (Positive); (2) trials to the unrewarded cue (Negative); (3) trials to one rewarded and one unrewarded cue (Mix). The Moss-Harlow effect was not observed. There were no differences in the performance of deprived and non-deprived animals

Harlow has maintained that the underlying process of discrimination learning is the elimination or suppression of response tendencies inappropriate to the learning situation. Harlow's uniprocess, inhibition learning theory has been supported by animal research, and what has become known as the Moss-Harlow effect, i.e., that monkeys learn to avoid an unrewarded stimulus with greater precision than they learn to choose a rewarded one, is a typical finding (Moss \& Harlow, 1947; Harlow, 1949; Leary, 1956). Recently, an attempt was made to demonstrate the Moss-Harlow effect in normal five-year-old children tested on a modified WGTA (Vaughter \& Cross, 1965). The results gave support, however, to a duo-process theory in which both reward and nonreward, both approach and avoidance cues are necessary for learning. These authors suggested that the data might reflect a species difference, i.e., that there is a phylogenetic progression from dependence upon avoidance cues to dependence upon both approach and avoidance cues.

If such a phylogenetic factor is operating, it was hypothesized that albino rats would demonstrate a dependence upon avoidance cues in discrimination as shown with monkeys. The purpose of the present experiment was to investigate further the possibility that a species difference does exist in regard to the nature of the process underlying discrimination learning.

On an elevated $Y$ runway, albino rats under one of two motivational conditions were tested on a duo-dimensional discrimination problem. Prior to discrimination trials, Ss were given one of three kinds of information about the reward contingencies to follow. In Positive information (PI) trials Ss received the rewarded cue; in Negative information (NI) trials Ss received the unrewarded cue; and in Mixed information (MI) trials Ss received one rewarded and one unrewarded cue.

In an attempt to imitate earlier studies with human Ss, half the animals were run under primary drive satiation; Eagle Brand milk was used as reward. It was hypothesized that non-deprived rats would show learning but that the performance of the deprived rats would be superior, supposing an additive drive function. Method

Subjects. Ss were 48 Sprague-Dawley albino rats. Animals were randomly assigned to the deprived or non-deprived condition and to one of three information conditions.

Apparatus. The apparatus was a modifiable elevated Y runway. Runways connected a starting stand to openings in the discrimination panel. A net hung under the stand and runways. The panel containing the two discrimination openings was removable in order that a second panel, containing a single opening could be inserted for information trials. Comparably, there were two sets of detachable runways; two $\mathrm{Y}$ shaped runways, one with black rough on the right and white smooth on the left, and one with white smooth on the right and black rough on the left; and a single munway with a white smooth surface on one side and a black rough surface on the other. Two goal boxes with $5 \times 6 \mathrm{in}$. swinging doors, one painted white and the other painted black, were singularly or simultaneously positioned behind the openings of the panels. The sides and floor of one goal box were lined with the white smooth cue (contact paper); the other was lined with the black rough cue (rubber material with ridges). Tops of the goal boxes were of Plexiglas. Goal cups were positioned at the rear of goal boxes. The start stand measured $31 \times 5 \times 8$ in. and was positioned $24 \mathrm{in}$. from the discrimination panel. The frame made of $1 \times 2$ 's and $1 / 4$ in. plywood containing the removable panels measured $24 \times 48$ in. Facing of $3 / 8$ in. plywood extended 6 in. from each side of the frame. The sliding panels of $3 / 8$ in. plywood were $17-1 / 2 \times 26$ in. with $6 \times 6$ in. openings. Y runways were $5 \times 17 \mathrm{in}$. and the straight runway was $5 \times 16 \mathrm{in}$, , both of $3 / 8 \mathrm{in}$, plywood. The goal boxes were $12 \times 6 \times 6$ in. cubicles.

Procedure. In all pre-training procedures, Ss were handled an equal number of times by the Es. The Ss were run under counterbalanced stimulus conditions; 24 were trained to the white smooth cue and 24 were trained to the black rough cue. Twenty-two hr. deprivation for the deprived group began at 60 days of age. Nondeprived animais were maintained on an ad lib food schedule. On days 4,5 , and 6 of deprivation, all Ss were given 2 min. adaptation in the to-be-rewarded (positive) goal box with $100 \mathrm{cc}$ of Eagle Brand milk in the goal cup. Training began for all Ss on day 7 of deprivation.

Each day all Ss received two information trials (either Positive, Negative, or Mix) with the single runway in position and a single discrimination trial with the $\mathrm{Y}$-shaped runway in position. PI consisted of $S$ running down the straight-away on two trials with the positive cue present and the response rewarded. NI consisted of the animal running down the straight-away on two trials with the nonrewarded cue present and the goal cup empty. MI consisted of one positive and one negative trial on the straight-away. Olfactory cues were controlled. Intertrial intervals were $1 \mathrm{~min}$.; Ss were detained in the goal box for $30 \mathrm{sec}$. Reward consisted of $20 \mathrm{cc}$ of Eagle Brand milk for all Ss. The Ss were given 18 discrimination trials. Position of the positive cue was randomized for each block for each $S$.

\section{Results}

In a completely randomized design with repeated measures, an analysis of variance was performed on the discrimination data. Total number of correct re- 


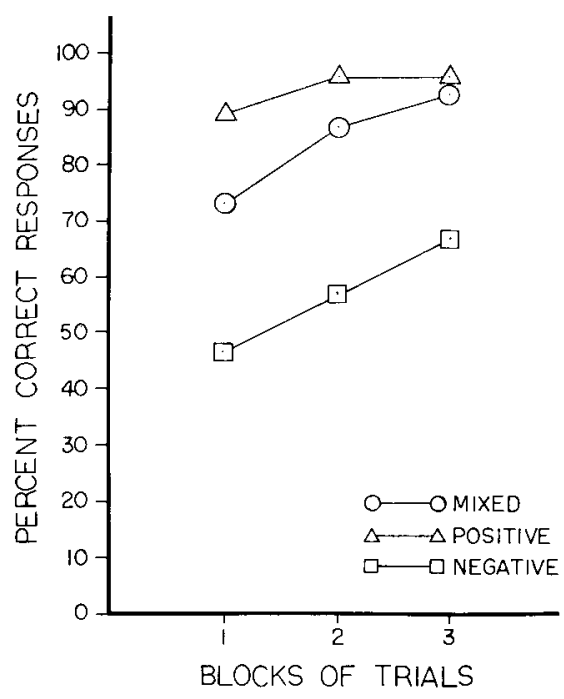

Fig. 1. Percent correct responses per block (transformed data).

sponses were grouped in blocks of six trials each. These raw scores were subjected to an arcsin transformation. Performance differed under the three information conditions $(F=9.72 ; \mathrm{d} f=2 / 32 ; \mathrm{p}<.001)$. A Newman-Keuls test revealed that $S s$ in the Group Positive performed significantly better $(p<.001)$, than either the Mix or Negative groups while the Group Mix Ss performed better than the Group Negative $(\mathrm{p}<.001)$. Discrimination improved over blocks $(\mathrm{F}=13.97 ; \mathrm{df}=2 / 72 ; \mathrm{p}<.001)$. There was no difference between the two stimulus conditions $(F=2.58 ; \mathrm{df}=1 / 36$ ) and there was similarly no difference between the performance of the deprived and non-deprived groups $(F=.14 ; d f=1 / 36)$. No interactions were statistically significant.

\section{Discussion}

The Moss-Harlow effect was not observed in naive rats of this study, At first glance, this finding seems to conflict with existing data, however, earlier primate studies have been done with sophisticated animals,i.e., animals having had previous discrimination training. This "sophistication" variable, although typically not stressed in discussions of the Moss-Harlow effect, may be crucial in demonstrating the utilization of the negative cue.

The Positive Group learned much about the correct response; however, the question is raised as to whether the Positive Group learned the reward contingencies of the two cues. Tolman (1932) stated that some practice on incorrect choices is necessary for gaining sophistication in the discrimination situation. Harlow's monkeys, demonstrating superior performance given Negative information, were sophisticated monkeys. Close examination of the data (Cross \& Brown, 1964; Riopelle, 1953) shows that monkeys in the Negative condition demonstrate performance that is inferior to that of the Positive Group during early acquisition and only later does their performance become superior. Behar (1961; 1962) also presents data supporting the conclusion that utilization of the negative cue must be acquired. The present study focuses on the early stages of learning in which Negative information may facilitate utilization of the negative cue. Positive information may retard later discrimination performance because of the preclusion of incorrect responses being made in the early trials. Thus, it is suggested that if the Ss in the present study, after having had experience under the various conditions, had been given a new discrimination task, the Negative Group would have performed significantly better than the other groups. Some tentative support is given to his suggestion since these Ss were given six trials of discrimination reversal and the Negative Group did perform better than either the Positive or Mixed Groups. The reversal data was not included in the analysis due to its brevity and inconclusiveness.

The hypothesis that the deprived animals would learn faster than the non-deprived animals was not supported. The elevated $\mathrm{Y}$-runway or the unusual incentive or the combination of the two might be responsible for this unexpected finding. Nevertheless, the demonstration that albino rats, without the presence of food deprivation, can learn and perform with such rapidity given adequate incentive is suggestive of theoretical and practical implications which should be examined.

\section{References}

Behar, I. Learned avoidance of nonreward. Psychol. Rep., 1961, $9,43-52$.

Behar, I. Evaluation of the significance of positive and negative cues in discrimination learning. J. comp. physiol. Psychol, $1962,55,502-504$.

Cross, H. A., \& Brown, L. T. Discrimination reversal learning in squirrel monkeys as a function of number of acquisition trials and prereversal experience. J. comp. physiol. Psychol., 1965, $59,429-431$.

Harlow, H. F. The formation of learning sets. Psychol. Rev., 1949, $56,51.65$

Leary, R. W. The rewarded, the unrewarded, the chosen, and the unchosen. Psychol. Rep., 1956, 2, 91-97.

Moss, Eileen M., \& Harlow, H. F. The role of reward in discrimination learning in monkeys. J. comp. physiol. Psychol., 1947, 40, 333-342.

Riopelle, A. J. Transfer suppression and learning sets. J. comp. physiol. Psychol., 1953, 46, 108-114.

Tolman, B. C. Purposive behavior in animals and man. New York: Appleton-Century Crofts, 1932.

Vaughter, Reesa M., \& Cross, H. A. Discrimination reversal performance in children as a function of prereversal experience and overlearning. Psychon. Sci., 1965, 2, 363-364.

\section{Note}

1. The authors gratefully acknowledge the assistance of Dr. H. A. Cross and the cooperation of the Borden Foods Company. 